\title{
Effort to Improve Rectal Anastomosis: the Triple-Stapled Technique for Rectal Anastomosis
}

\author{
Sung Il Kang \\ Division of Colorectal Surgery, Department of Surgery, Yeungnam University Medical Center, Yeungnam University College of Medicine, \\ Daegu, Korea
}

\section{See Articles on Page 16-20}

The restoration of intestinal continuity has been made by handsewn anastomosis, a method as old as surgery itself [1]. The concept of using compression or stapling devices for intestinal anastomosis was initiated in the early 1800 s, and has since been further developed $[1,2]$. However, stapled colonic anastomosis specifically was popularized after Goligher et al. [3] reported colorectal anastomosis using the modern stapled device in 1979.

There are several advantages of using an anastomotic stapling device for colorectal anastomosis. Compared with hand-sewn anastomosis, a stapling device ensures a consistent stapling bite distance and reduces the procedure time. In addition, circular staplers, which are generally used for colorectal anastomosis, are designed to provide an easy approach to anastomotic sites located in the deep pelvic space. A stapled colorectal anastomosis is expected to have superior anastomotic success than hand-sewn colorectal anastomosis theoretically. However, these advantages of a stapled anastomosis do not guarantee successful colorectal anastomosis compared with hand-sewn anastomosis. The most recent Cochran review reported no superiority of stapled over handsewn techniques in colorectal anastomosis [4].

Most stapled anastomosis after colorectal resection are performed using double-stapled anastomosis (DSA), in which the rectal stump is closed with a linear stapler followed by colorectal anastomosis with a circular stapler [4-6]. During DSA, the end of

Correspondence to: Sung II Kang, M.D.

Division of Colorectal Surgery, Department of Surgery, Yeungnam University Medical Center, Yeungnam University College of Medicine,

170 Hyeonchung-ro, Nam-gu, Daegu 42415, Korea

Tel: +82-53-620-3580, Fax: +82-53-624-1213

E-mail: sungiry@naver.com

ORCID: https://orcid.org/0000-0002-4751-5779

(C) 2021 The Korean Society of Coloproctology

This is an open-access article distributed under the terms of the Creative Commons Attribution NonCommercial License (https://creativecommons.org/licenses/by-nc/4.0) which permits unrestricted noncommercial use, distribution, and reproduction in any medium, provided the original work is properly cited. the proximal colon is opened and the anvil of the stapler is inserted into the proximal colon, followed by open-end closure via the purse-string suture method. Some surgeons are concerned that this process increases the risk of contamination at the surgical site. Moreover, it is difficult to achieve closure via the pursestring method when the colon is dilated or edematous [7]. Along with the aforementioned reasons, foreign body reactions caused by metal stapling may negate the advantages of stapling and be associated with the non-superiority of stapled over hand-sewn anastomosis.

The current study concerns the triple-stapled anastomosis (TSA) technique for colorectal anastomosis [7]. To the best of my knowledge, TSA in colorectal anastomosis was introduced in 1989 [8]. Subsequently, only a few studies on similar technical methods have been reported $[9,10]$.

The authors have suggested that TSA can minimize fecal spillage because the purse-string suture method is not required. Concerns regarding the size disparity between the proximal colon and the rectal stump could also be more easily addressed in TSA than in DSA. In addition, the operative time was decreased for TSA compared to that for DSA, due to the elimination of the pursestring suture procedure (mean of minutes, TSA vs. DSA: 242.8 vs. 306.1, $\mathrm{P}=0.001$ ) [7]. However, the key factors associated with successful colorectal anastomoses, such as anastomotic leakage rate and incidence of other complications, did not differ between TSA and DSA in the current study.

The major disadvantage of the TSA technique is that it incurs a higher cost than does DSA, because of an additional linear stapler and cartilage for resection and closing of the proximal colon. Mahid et al. [10] suggested that the TSA technique costs approximately 450 US dollars more than the DSA technique. They asserted that the additional cost was offset by the shortened operative and anesthesia time. In the current study, the authors justified the additional cost of TSA in the same way [7]. However, since the situation is different in Korea, where medical expenses are relatively lower than those in the United States, I have doubts about that.

Despite its limitations, the current study is meaningful in being 
one of only the few studies concerning TSA for colorectal anastomosis. More research will be needed in order for TSA to be equally as justifiable as DSA, which is currently widely used in colorectal anastomosis.

\section{CONFLICT OF INTEREST}

No potential conflict of interest relevant to this article was reported.

\section{REFERENCES}

1. Moran BJ. Stapling instruments for intestinal anastomosis in colorectal surgery. Br J Surg 1996;83:902-9.

2. Kaidar-Person O, Rosenthal RJ, Wexner SD, Szomstein S, Person B. Compression anastomosis: history and clinical considerations. Am J Surg 2008;195:818-26.

3. Goligher JC, Lee PW, Macfie J, Simpkins KC, Lintott DJ. Experience with the Russian model 249 suture gun for anastomosis of the rectum. Surg Gynecol Obstet 1979;148:516-24.

4. Neutzling CB, Lustosa SA, Proenca IM, da Silva EM, Matos D. Stapled versus handsewn methods for colorectal anastomosis sur- gery. Cochrane Database Syst Rev 2012;(2):CD003144.

5. Illuminati G, Carboni F, Ceccanei G, Pacilè MA, Pizzardi G, Palumbo $\mathrm{P}$, et al. Long-term evaluation of a modified double staple technique for low anterior resection. Acta Chir Belg 2014;114: 338-43.

6. Radovanovic Z, Petrovic T, Radovanovic D, Breberina M, Golubovic A, Lukic D. Single versus double stapling anastomotic technique in rectal cancer surgery. Surg Today 2014;44:1026-31.

7. De Robles MS, Young CJ. Triple-staple technique effectively reduces operating time for rectal anastomosis. Ann Coloproctol 2021;37:16-20.

8. Julian TB, Ravitch MM. Evaluation of the safety of end-to-end (EEA) stapling anastomoses across linear stapled closures. Surg Clin North Am 1984;64:567-77.

9. Balaji NS, Macklin CP, Fawole S, Aster AS, Rao VS, Moore PJ, et al. The 'modified triple staple' technique: a variant stapling technique for anastomosis after low anterior resection. Surgeon 2007;5:199-201.

10. Mahid S, Galandiuk S, Christmas B, Tran D. Triple-staple technique for low rectal anastomoses eliminates the purse-string suture and facilitates stapled colorectal anastomosis. J Am Coll Surg 2006;202:382-3. 